\title{
EDUCAÇÃO INFANTIL: APRENDIZADOS NA BRINQUEDOTECA UNIVERSITÁRIA*
}

Elni Elisa Willms (UFMT)

A gente cresce sempre, sem saber para onde.

(ROSA, João Guimarães, 2001, p. 103)

\section{Introdução}

O objetivo deste texto é refletir sobre o brincar no âmbito das experiências de pesquisa na brinquedoteca universitária do curso de Pedagogia da Universidade Federal de Rondonópolis. Trata-se de um exercício teórico de cunho antropológico em que se volta o olhar para dois relatos do Diário de Campo da Brinquedoteca ${ }^{1}$, de 2019, para deles deixar reverberar alguns aprendizados. Por ocasião do Curso de Qualificação de professores em parceria com a SEMED e a UFR, em 2020, coube-me o módulo sobre Currículo e Movimento na Educação Infantil, e este texto é o meu movimento escrito de deixar algumas pistas de como pode ser o trabalho dos educadores com as crianças dessa etapa da Educação Básica quanto ao brincar.

No início do ano de 2020, Angela Lima Bittencourt defendeu a dissertação de mestrado, sob nossa orientação, no Programa de Pós-Graduação em Educação da UFMT intitulada "É onde vivem os brinquedos: contribuições de uma brinquedoteca universitária de Rondonópolis para a formação de profissionais da educação infantil" (BITTENCOURT, 2020). O estudo apresenta um histórico de como a brinquedoteca da UFMT/CUR (Laboratório Especial de Ludicidade/Brinquedoteca Profa. Dra. Soraiha Miranda de Lima) se constituiu e como contribui para o processo de formação das acadêmicas de Pedagogia².

\footnotetext{
"DOI - 10.29388/978-65-86678-68-0-0-f.71-84

${ }^{1}$ Nosso trabalho na brinquedoteca sempre foi inspirado pelas contribuições da Antropologia, por isso as participantes do projeto de extensão foram incentivadas a narrar por escrito o que observavam durante os atendimentos, construindo-se assim um Diário de Campo, fonte de pesquisa para produções acadêmicas.

${ }^{2}$ Quando fizermos referências a pedagogas, estudantes, bolsistas e voluntárias que participaram da pesquisa o faremos sempre no gênero feminino, pois majoritariamente o curso de pedagogia é constituído de mulheres; em 2019 tivemos a experiência de um estudante homem como voluntário na brinquedoteca.
} 
Por cerca de quatro anos desenvolvi atividades de coordenação e pesquisa nesse espaço. Na universidade há os que trabalham nos laboratórios e com ciências exatas, e isso é muito importante! De forma análoga, como pedagogas, trabalhamos com o movimento sempre cambiante das crianças, com as culturas infantis, e esse campo de estudos é algo igualmente fundamental para a universidade e para o curso de pedagogia! Nesse sentido, a brinquedoteca:

Tem como principal objetivo proporcionar às crianças, da faixa etária de 4 a 6 anos, matriculadas em escolas de Educação Infantil da rede pública municipal de Rondonópolis, bem como aos professores que as acompanham, um espaço de produção da cultura infantil e da realização de práticas educativas mediadas pelo brincar. É uma iniciativa que está diretamente vinculada à implementação de uma política pública voltada para a infância e para um direito inalienável da criança, que é o direito de brincar e o de ter acesso a espaços para o exercício desse direito. A Brinquedoteca, ao se definir como espaço voltado para a produção cultural da infância, visa implementar ações destinadas à afirmação da criança como protagonista das experiências que marcam seu tempo de vida e como cidadã (UNIVERSIDADE FEDERAL DE MATO GROSSO, 2019).

Como coordenadora da Brinquedoteca, sempre contei com a presença de uma ou duas bolsistas e muitas estudantes voluntárias, a maioria do curso de Pedagogia, mas também dos cursos de Psicologia e Enfermagem. Com a bolsista Thaís Cristina Pessoa Ramos produzimos um texto sobre experiências performáticas com os poliedros e com o carrinho de rolimã (WILLMS e RAMOS, 2018), nesse texto também contamos como está organizada nossa brinquedoteca, como foi construído o seu acervo e como se dá o seu funcionamento.

Nos atendimentos semanais, com duração de duas horas, recebíamos as crianças da Educação Infantil da rede pública municipal de Rondonópolis para brincar do que quisessem. $O$ ambiente era especialmente preparado para este fim: brincar livremente. As bolsistas e voluntárias, além de estudar e ler sobre o brincar, sobre as crianças e as culturas infantis, mantinham o espaço sempre organizado e permaneciam - durante os atendimentos - em atitude de disponibilidade, observando e cuidando enquanto também refletiam sobre alguns aspectos que envolvem o brincar, as crianças e a infância. O livro Território do brincar, organizado por Renata Meire- 
les (2015) foi um dos que lemos em nossos estudos e dele me sirvo para fundamentar as narrativas a seguir.

\section{Quando a criança é respeitada na iniciativa de brincar - narrativa de 18/06/2019}

Criança é assim mesmo: acostumada a andar às bordas, a pegar pelas beiradas, a se instruir com os olhos espichados de longe, a ver de luneta quando não é permitido se aproximar.

(PIORSKI, Gandhy, 2015, p. 87)

Vou me ater a duas narrativas feitas por mim logo após os atendimentos dos dias 18/06/2019 e 11/06/2019, ambos no período matutino. Observar as crianças nesses atendimentos semanais foi sempre uma experiência de re-encantamento com as culturas infantis, com a potencialidade das crianças, a criatividade, seus universos tão desafiadores e que tanto podem nos ensinar! Como professora, eu seguia o que indica Gandhy Piorski na epígrafe acima: espichava meu olhar para melhor apreciar as crianças. Nem sempre chegar perto demais delas, enquanto brincam, nos é favorável: parece que algo se desfaz e que uma intimidade ali precisa ser respeitada. Por isso, observar, um pouco de longe, sempre nos pareceu uma boa escolha metodológica até como respeito a esse momento tão íntimo em que uma criança, às vezes só ou acompanhada, se põe a construir um cosmos. "Nesses ambientes de solidão e de brincadeiras [...] criam-se vínculos. [...] A criança faz a síntese simbiótica do cosmos primeiro, fraternus, de seus pares com suas próprias experiências de intimidade e repouso" (PIORSKI, 2016, p. 86, grifo do autor). Assim, eu percebia que os mesmos brinquedos podem sempre ser reinventados pelas crianças, verdadeiras artesãs da cultura. Adriana Friedmann indica a intencionalidade antropológica dessa nossa escolha:

Ser ou tornar-se antropólogo, pesquisador, observador dos universos infantis não depende unicamente de ter estudado antropologia. É necessário, sim, compreender os conceitos fundantes desta ciência social a fim de assimilar que o ponto de partida dessas "viagens" acontece desde um outro território: a paisagem do outro. Entender que a postura é totalmente diferente da de um educador-professorensinante (FRIEDMANN, 2015, p. 42). 
De posse das muitas leituras que o curso de pedagogia oferece nas suas mais variadas disciplinas, incorporei as contribuições da antropologia para me aproximar aos poucos desse outro, a criança, sua cultura e seu brincar, para a partir desse olhar e desse encontro de alteridades aprender com ela. Novamente o mestre de culturas da infância nos inspira e ampara:

Brincar é de fato real e muito agrada as crianças, pois se sabe conhecimento, tem significância, tira seu substrato da vida palpável, aplica a visão e toda sua subjetividade para o pulso da comunidade, para as artérias do trabalho, constrói-se afetiva e comum a todos. Brincar é como um soro silencioso, gotejante, invisível, percorre por dentro, ensina por via venal os modos de apreender o sumo do mundo (PIORSKI, 2015, p. 85-86).

Acredito que como pedagogas é preciso que tenhamos sensibilidade para olhar esse outro e sua maneira tão intensa de "apreender o sumo do mundo". As crianças com suas imaginações tão férteis ousam explorar a matéria do mundo com todos os sentidos muito abertos e com curiosidade sempre renovada olham, tocam, cheiram, ouvem, saboreiam e intuem tudo quanto podem, e assim vão internalizando experiências afetivas, construindo laços. É nesse sentido que escrevemos, noutro texto, as contribuições de uma educação de sensibilidade (WILLMS, 2020).

A brinquedoteca da UFMT/Rondonópolis possui um conjunto de brinquedos chamado poliedros. Tenho observado os poliedros com a intenção de perceber como as crianças interagem com suas peças. Poderia olhar e observar muitos outros brinquedos e aspectos, entretanto, nunca conseguimos apreender a miríade de movimentos que se passam nessas duas horas de atendimento na brinquedoteca. Por isso, o recorte do olhar se dirige ora para um, ora para outro evento, enquanto, de alguma forma, cuidamos do todo. Os poliedros foram construídos por iniciativa de um professor e

[...] pelas turmas de 2으, 3ㅇ e 4ㅇaㅇ anos de Pedagogia, em 2014, quando cursaram as disciplinas Sociologia da Educação, Brincar e Educação e Arte-Educação, da UFMT/CUR, ministradas pelo Prof. Dr. Marlon D. Trevisan. O trabalho foi doado à brinquedoteca do Câmpus [...]. Trata-se de 50 poliedros (sólidos geométricos), de diversas dimensões, cubos e paralelepípedos. Foram confeccionados pela marcenaria da UFMT, Câmpus de Cuiabá, em seguida, lixados e pintados de branco pelos graduandos, para finalmente receberem as cores: branco, azul celeste, cinza, bege e laranja, todas em esmalte. 
Cerca de 120 pessoas foram envolvidas no processo de construção do grande brinquedo. Por sua natureza mutante, a instalação tem servido à educação matemática, ao movimento, à dramatização, ao brincar livre, especialmente, à criação, pelas crianças, de zonas circunscritas, dentre vários outros aspectos da ludicidade (TREVISAN et al., 2015, p. 01).

Hoje eu observei que um menino brincou o tempo todo com os poliedros, ou seja, desde a chegada às 8 h15 até o momento em que a coordenadora da escola os convocou a organizar os brinquedos, por volta das $10 \mathrm{~h}$. O que ele fazia? Movimentava as peças daqui para ali, empilhava, enfileirava, endireitava uma peça para ficar parelha com a outra, carregava, subia em cima das peças, observava, olhava, descia, pulava, aceitava a ajuda de uma ou outra criança - menino ou menina - que ele acolhia, sempre silenciosamente, nessa labuta de criar e construir algo. Eu não pude ficar perto para ouvir o que elas conversavam. A uma certa distância, com a intenção de também atender e cuidar de todos os outros, eu observava um movimento harmônico. Não houve disputas, mas uma coordenação gentil de movimentos entre ele e as outras crianças que entravam e saiam com muita liberdade daquele cosmos criado por ele com tanto "enthousiasmós (entusiasmo - en-theos - possuído por um poder divino, inspirado)". (PIORSKI, 2016, p. 85, grifos do autor). Perguntei para a professora o nome e a idade do menino, e ela disse: 5 anos, e ele é muito silencioso, quieto, mas muito inteligente.

Eu percebi nele uma criança muito diligente e concentrada. Enquanto todas as outras crianças correram muito e exploraram todos os espaços dentro e fora da brinquedoteca, movimentaram-se, pularam, saltaram, pediram ajuda porque queriam andar na bicicleta (só temos uma) ou nos patinetes (temos dois) ou passaram de um para outro brinquedo - e tudo isso é legítimo e próprio da cultura do brincar - esse menino escolheu, por si, brincar detidamente apenas com essas peças. E ele foi respeitado nessa sua escolha.

Eu não conseguiria enumerar todos os movimentos dele. Não é isso que nos interessa. O que encanta - e nos educa - é capturar, observar, valorizar e registrar o protagonismo infantil. Essa capacidade única que as crianças têm de reinventar o mundo, de manipular os objetos e com isso descobrir suas potencialidades. Esse menino construtor ensinou-me, uma vez mais, a respeitar a iniciativa das crianças, a olhar para esse universo que é do outro, como apontou Friedmann (2015) acima. Com peças que 
estavam adequadas ao tamanho dele, foi fazendo sempre uma nova construção.

Como pedagogas é importante que respeitemos o espaço e o tempo do brincar para que a criança exerça sua criatividade, para que tenha protagonismo, para que seja o que ela quer ser! Explorar as peças dos poliedros que, de alguma forma, são quase de seu tamanho, de madeira, com um peso considerável para a manipulação, deve ter sido algo que trouxe muita satisfação para esse menino! Durante esses quatro anos que cuidei da brinquedoteca e observei o brincar, eu nunca tinha visto uma criança ficar somente nesse brinquedo por tanto tempo!

Enquanto dentro da brinquedoteca outras crianças exerciam o direito de brincar do que escolheram brincar, no saguão eu observei - e regis trei por meio da foto a seguir - o intenso movimento das crianças com os mais diferentes brinquedos: bambolês, carrinhos, bicicleta, patinetes, bola etc. Andar ou perambular pelo espaço e observar os outros também faz parte da cultura infantil do brincar que expressa tanto o que é ser criança!

Figura 1 - Menino entusiasmado para brincar e o saguão da brinquedoteca

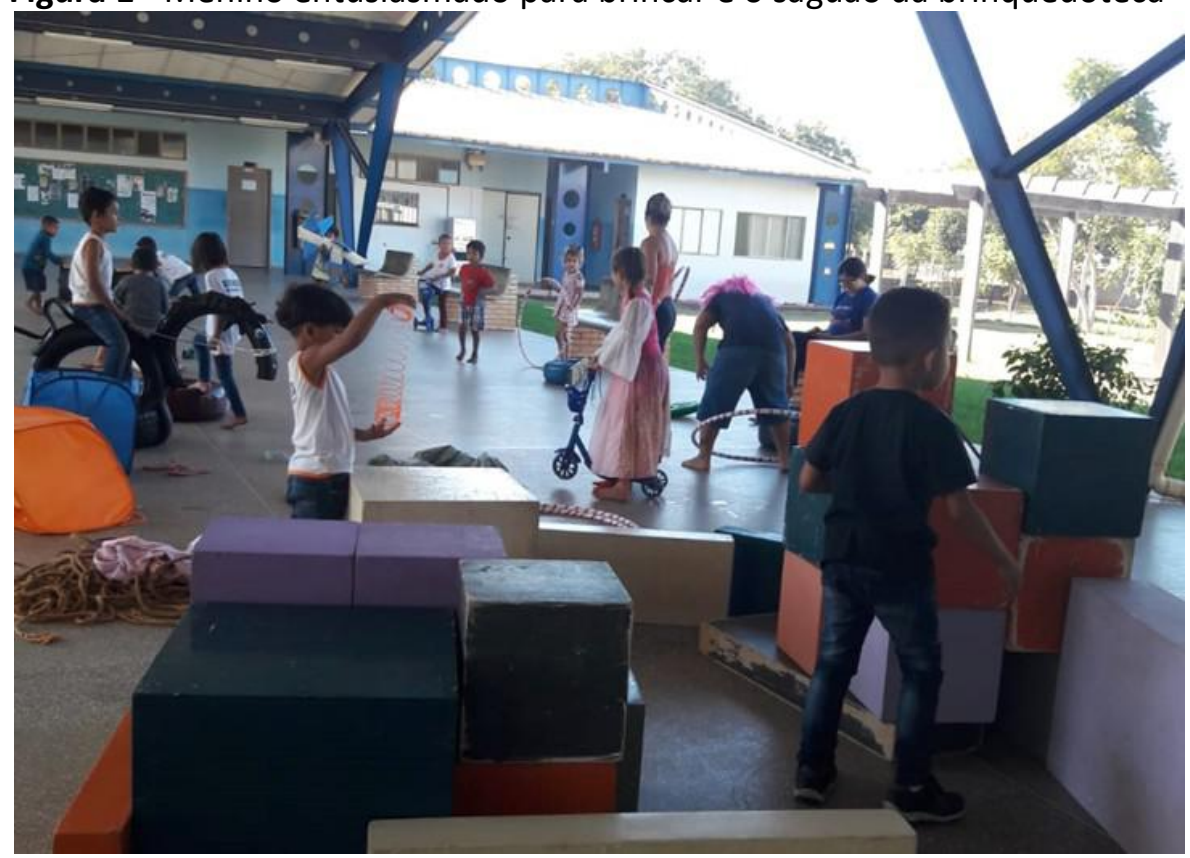

Fonte: Acervo da Brinquedoteca 2019 
Enquanto isso, o menino construtor seguia no seu labor a explorar aquele espaço e aquelas peças. Aprendendo o quê? Aperfeiçoava em si o que ele é, do jeito que escolheu e brincava sendo criativo. Acreditamos que é fundamental a criança ter espaço e tempo para ser e fazer o que escolher, sem a interferência, ordenamento ou controle dos adultos ditando para fazer isso ou aquilo. Após quatro anos a observar as crianças, podemos afirmar: elas conseguem por si mesmas encontrar algo prazeroso com que se ocupar. Nosso papel na brinquedoteca é observar, respeitar e registrar esse protagonismo infantil: aprendemos com as crianças.

O brincar desse menino tão autônomo continua a ecoar como algo para ser publicado e por isso este texto deixa reverberar os sentidos das palavras de Marcos Ferreira-Santos como uma maneira de reafirmar a importância do brincar e sua observação:

Seria preciso desconstruir os dois principais fantasmas que engendram as escolas: as teorias do desenvolvimento (herdeiras do pensamento cartesiano, que tudo separa) e o paradigma da imitação (a mimesis aristotélica, prima-irmã da lógica da identidade e, portanto, da exclusão no mundo ocidental). A criança não cumpre estágios de desenvolvimento como um software pré-programado em torneios de videogame, a saltar por fases preestabelecidas. A jornada humana é muito mais do que isso, é pro-jectum existencial sempre inacabado. E quem vê no gesto da criança apenas a imitação do mundo adulto jamais perceberá que ela reinventa, a seu modo, o mundo que se apresenta ante seus olhos e mãos. Quem recusa essa tarefa humana, rápido se rende à cópia, à reprodução, à memorização sem sentido (FERREIRA-SANTOS, 2015, p. 96, grifos do autor).

Todo o conjunto de leituras que fazemos sobre as crianças deve dialogar com a prática de observá-las enquanto brincam. Por vezes, é preciso abandonar algumas teorias, como as desenvolvimentistas, citadas acima, que tendem a engessar o processo criativo tão pulsante nas crianças. É preciso, também, revisitar o conceito de que as crianças apenas imitam o mundo do adulto. Ao contrário, elas criam e recriam, o tempo todo, a partir daquilo a que têm acesso. Assim, como pedagogas, poderemos nos educar para esse outro e sua cultura, essa criança que chega ao mundo e que precisa tudo apreender para criar e transformar a cultura. Para além da imitação, o que percebemos ao observar crianças é uma intensa criatividade que 
se fortalece como autonomia quando há espaço e tempo disponíveis para brincar. Passemos a outros aprendizados da segunda narrativa.

\section{Para mim é sempre uma alegria não saber: o que será que vai acontecer? 11/06/2019}

O brincar não tem outra finalidade se não ele mesmo. A satisfação da criança ao brincar é a de perceber-se um ser humano. Quando a finalidade surge em alguma atividade, torna-se trabalho - tarefa dos adultos. $O$ adulto pode ser realmente criativo e autônomo quando a finalidade maior de seu trabalho significar também crescimento.

(LAMEIRÃO, Luiza, 2015, p. 78)

Eu gosto muito de observar as crianças criando sempre formas novas de brincar com os poliedros. Na semana passada, eu observei quando três ou quatro meninas e meninos começaram a empilhar os poliedros menores. Foram pondo um em cima do outro, depois outro, mais outro, e mais outro de maneira a ficar uma grande torre mais alta do que eu, que tenho $1,77 \mathrm{~m}$. Como elas fizeram isso? Subiram em cima de um poliedro e com eles foram ganhando cada vez mais altura. Por fim, as crianças pediram a um estudante e voluntário, o Gabriel (que também é alto), para que colocasse a última peça. E olharam, admiradas, para algo que tinham feito e que era maior do que elas! Isso mostra o que é crescer junto com os outros no mundo!

Dessa vez observei que elas empilhavam os poliedros todos bem juntos, formando um bloco homogêneo. O movimento começou espontaneamente a partir delas. Nada foi combinado. Um menino pegou uma peça e colocou-a aqui, outro pôs outra peça ali, uma menina leva outra peça e, aos poucos, algo vai surgindo. Para mim é sempre uma alegria não saber: o que será que vai acontecer? Observo com paciência e entusiasmo! Depois que elas fizeram esse pequeno bloco que parecia um cercado - talvez um castelo? Mas pode ser que fosse outra coisa totalmente diferente - eu percebi, então, que havia um gosto por subir nos poliedros. O corpo todo das crianças envolvido no movimento de ascensão: mãos, braços, pés, cintura, joelho, pescoço, cabeça. Força e determinação! Cresciam nossas crianças nesse brincar de elevar-se!

Carregar as peças também é um esforço para alguns. Um dos meninos pediu-me ajuda para pegar uma das peças grandes que estava no chão. A peça é realmente grande até para eu que sou alta e adulta. Depois eu 
percebi que dois meninos entraram espontaneamente em colaboração: juntos pegaram e movimentaram a peça. Seguiu a brincadeira de subir e empilhar, livremente. Havia uma harmonia no movimento das crianças, principalmente porque tudo partia delas.

Quatro professoras das turmas que acompanham as visitas observavam essa construção. Eu intervi num momento com uma professora e disse para ela deixar que as crianças brincassem, pois ela estava a dizer: "Não, não faça isso, você vai se machucar, isso é muito pesado". A Viviane (voluntária) também já tinha observado que uma das professoras havia retirado alguns meninos de perto dos poliedros porque, segundo ela, eles poderiam se machucar. Contrariando tudo, as crianças não se machucaram, brincaram em tranquilidade. Por outro lado, num determinado momento, uma das professoras observou uma menina que estava há algum tempo parada em cima dos poliedros a olhar para o chão. A professora perguntou se ela queria pular e a menina disse que sim. Então, como que sentindo-se segura e autorizada, ela pulou! Na sequência, outras crianças, meninos e meninas, entraram nessa brincadeira que surgira espontaneamente, e também pularam. Subiam e pulavam com elegância, segurança e firmeza. Primeiro pularam no chão, depois fizeram uma espécie de pista onde pulavam e seguiam correndo em circuito. Quando eu vi isso acontecer procurei capturar o momento do pulo, do voo, da vertigem! Foi bonito!

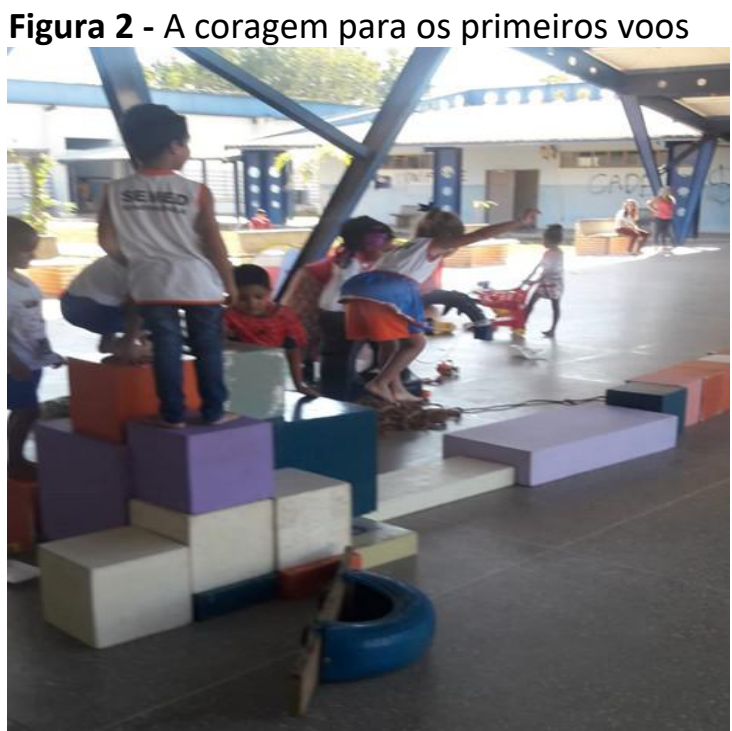

Fonte: Acervo da Brinquedoteca, 2019 
A iniciativa, a coragem das crianças, a ousadia, a criatividade, tudo ali, em ato, num movimento livre e criado espontânea e inteiramente por elas. Estavam a saltar e voar fora do chão! Foi lindo flagrar - ainda que um tanto fora de foco - o voo do Batman, um menino chamado João!

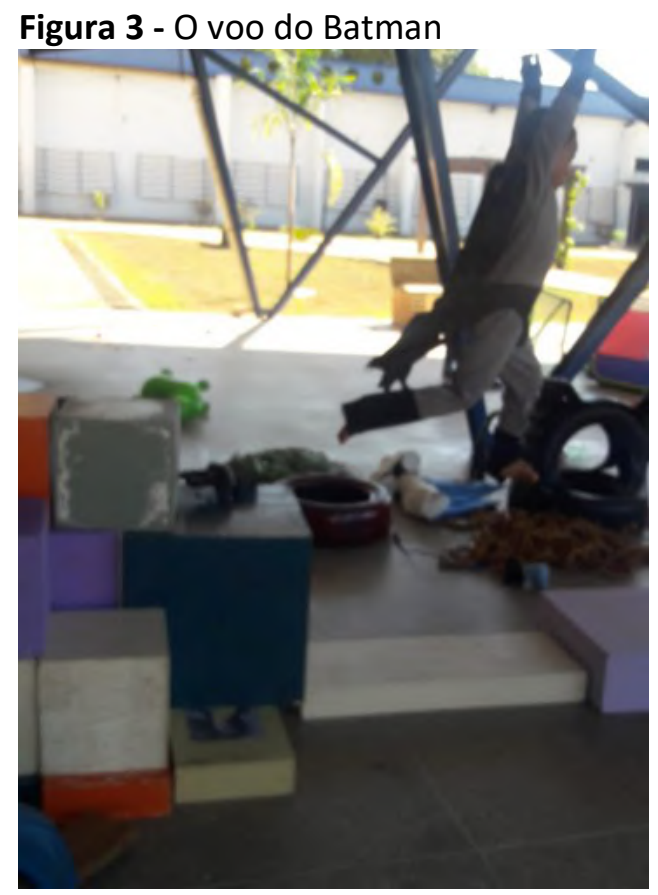

Fonte: Acervo da Brinquedoteca 2019

Solto no ar! Os braços para cima como se esticasse as asas, a capa espécie de extensão das asas - a acompanhar todo o voo! Um menino a voar a partir dos poliedros aqui na nossa brinquedoteca! Algo tão efêmero, tão sútil, aconteceu num átimo de um segundo, mas aconteceu para os olhos de quem sabe ver! Aconteceu o movimento da leveza e da coragem para este menino poder voar. Trago aqui as palavras de Luiza Lameirão, uma pesquisadora do brincar tradicional, como a comprovar a grandeza deste gesto ao mesmo tempo tão simples e tão solene:

Cada vez que a criança corre, salta, se movimenta com leveza, com domínio do próprio corpo, suas ações significam autonomia significam que a "casa" Ihe pertence e que a criança está saudável dentro de si. A leveza é a característica mais significativa a ser 
observada quando nos detemos diante da habilidade corpórea (LAMEIRÃO, 2015, p. 77).

Um Menino Morcego estava vivo na brinquedoteca e se apresentou! Solto, livre, leve, autônomo e ousado! A minha alegria foi enorme também! Essa leveza e, ao mesmo tempo, essa coragem de se lançar no mundo, primeiramente assim brincando, para logo mais adiante esse mesmo menino apropriar-se de outros espaços. O corpo já treinado nesse voo inicial há de impulsioná-lo a outras conquistas de si mesmo vida afora. Que bom que ele pode nos educar com esse voo. Ele e todas as crianças sempre estão a renovar o mundo com suas presenças. Que possamos, como pedagogas, nos deixar tocar por essa alegria e leveza, coragem e beleza de nos lançarmos à conquista de sermos nós mesmas.

Nosso objetivo foi modesto: trazer a público duas narrativas sobre o brincar, anotadas durante os atendimentos na brinquedoteca do curso de pedagogia da UFMT de Rondonópolis. Momentos fugazes que evidenciam, entretanto, a riqueza que há nas culturas infantis expressas pelas crianças por meio do brincar livre. Como adultas, garantimos o tempo e o espaço. Organizamos e cuidamos do ambiente. Ficamos ali disponíveis. Observamos e registramos essas experiências em nosso Diário de Campo. Aprendemos muito. As crianças por si mesmas se põem no movimento de crescer, como anunciado por João Guimarães Rosa na epígrafe inicial deste texto, sem que saibamos muito bem para onde, elas seguem. E, assim, concordamos com Luiza Lameirão na epígrafe desta seção final: brincar não tem finalidade, porém torna a criança humana. Para isso é preciso

[...] estarmos atentos, sempre alertas, sempre abertos, ouvir e escutar, olhar e observar. Não só mundo afora, mas também mundo adentro. Isso garante que o sujeito constitua em si o atributo essencial que o torna humano: a autonomia, que é a capacidade de se reger com base em leis próprias. Quando ele se move baseado em suas próprias leis, torna-se autor. $\mathrm{O}$ " $\mathrm{r}$ " agregado à palavra "auto" evidencia que o ser humano se colocou em movimento (LAMEIRÃO, 2015, p. 80).

Nesse olhar mundo adentro, fica o convite para cada pedagoga da Educação Infantil constituir também em si essa leveza e autonomia de ser livre e de permitir que as crianças brinquem. É preciso educar a paciência da pedagoga para olhar essa atividade tão intensa e tão bonita que é ver o movimento da criança crescer no labor de descobrir o mundo, descobrindo 
a si na relação com os outros. Este texto pretendeu contribuir nesse sentido.

\section{Referências}

BITTENCOURT, Angela Lima. “É onde vivem os brinquedos”: contribuições de uma brinquedoteca universitária de Rondonópolis para a formação de profissionais da educação infantil. 2020. Dissertação (Mestrado em Educação). PPGEdu. Universidade Federal de Mato Grosso. Rondonópolis, 2020.

FERREIRA-SANTOS, Marcos. Território da iniciação: o brincar escapulindo das trancas e trincas. In: MEIRELLES, Renata (org.). Território do brincar: diálogo com escolas. São Paulo: Instituto Alana, 2015. p. 90-101.

FRIEDMANN, Adriana. O olhar antropológico por dentro da infância. Adentrando nas casinhas das crianças. In: MEIRELLES, Renata (org.).

Território do brincar: diálogo com escolas. São Paulo: Instituto Alana, 2015. p. 37-45.

LAMEIRÃO, Luiza. Ninguém é tão grande que não possa aprender nem tão pequeno que não possa ensinar: o autoconhecimento do educador. In: MEI RELLES, Renata (org.). Território do brincar: diálogo com escolas. São Paulo: Instituto Alana, 2015. p. 76-81.

MEIRELLES, Renata (org.). Território do brincar: diálogo com escolas. São Paulo: Instituto Alana, 2015.

PIORSKI, Ghandy. Náufragos e piratas do aprendizado. In: MEIRELLES, Renata (org.). Território do brincar: diálogo com escolas. São Paulo: Instituto Alana, 2015. p. 82-89.

. Brinquedos do chão: a natureza, o imaginário e o brincar. São Paulo: Peirópolis, 2016.

ROSA, João Guimarães. Primeiras estórias. 15.ed. Rio de Janeiro: Nova Fronteira, 2001. 
TREVISAN, Marlon Dantas et al. Instalação artística e lúdica "poliedros imanentes": estendendo o alcance da brinquedoteca. In CONPEduc, 2015, Rondonópolis, Anais... Rondonópolis, UFMT/CUR, 2015.

\section{UNIVERSIDADE FEDERAL DE MATO GROSSO. Projeto Laboratório Especial} de Ludicidade/ Brinquedoteca Professora Doutora Soraya de Miranda Lima. Protocolo SIEX 270220181341591883. Cuiabá, 2019. Disponível em: http://www1.ufmt.br/ufmt/un/secao/12624/pedagogiacur. Acesso em: 01 out. 2019.

WILLMS, Elni Elisa; RAMOS, Thaís Cristina Pessoa. O brincar livre na brinquedoteca da UFMT/CUR: experiências performáticas com os poliedros e com o carrinho de rolimã. In: CARDONA, Ana Cecilia Osorio; CAMARGO, Mercedes Rodriguez; MENEZES, Roni Cleber Dias de. Red de educación Contemporánea en Latinoamérica: tendencias latinoamericanas en investigación. Volumen II. Bogotá: Universidad La Gran Colombia, 2018. . Educação de sensibilidade: a maestria dos saberes tradicionais. Revista da Faculdade de Educação (Universidade do Estado de Mato Grosso), Vol. 33, Ano 18, № 1, p. 177-207, jan./jul., 2020. Disponível em: https://periodicos.unemat.br/index.php/ppgedu/article/download/4791/3 676. Acesso em: 02 nov. 2020. 